\title{
Compositionally distinct overlying hotspot tracks in the South Atlantic: Do primary mantle plumes trigger secondary upwellings?
}

S. HomrighaUSEN ${ }^{1 *}, \mathrm{~K}_{\text {. HOERNLE }}^{1,2}, \mathrm{H}_{\text {.ZHOU }}{ }^{1}$, J.

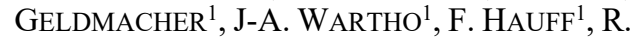
WERNER $^{1}$, S. JUNG ${ }^{3}$, J. P. MORGAN ${ }^{4123}$

${ }^{1}$ GEOMAR Helmholtz-Zentrum für Ozeanforschung Kiel, Kiel, Germany

${ }^{2}$ Institut für Geowissenschaften, Christian-Albrechts Universität zu Kiel, Kiel, Germany

${ }^{3}$ Mineralogisch-Petrographisches Institut, Universität Hamburg, Hamburg, Germany

${ }^{4}$ Royal Holloway, University of London, Department of Earth Sciences, Egham Hill, UK

The age-progressive Tristan-Gough and Shona volcanic tracks on the southern South Atlantic seafloor share a common Enriched Mantle (EMI-type) geochemical signature throughout their long histories (c. $132 \mathrm{Ma}$ and $180 \mathrm{Ma}$, respectively). Our new geochronological and geochemical data, combined with literature data, show that both EMI-type hotspot tracks are overlain by age-progressive volcanic tracks with St. Helena-type HIMU (high time-integrated ${ }^{238} \mathrm{U} / 204 \mathrm{~Pb}$ ) compositions, which extend into southwest Africa. The systematic age difference of 30-40 Ma between the EMI and HIMU volcanism at any given location corresponds to a distance of $900-1200 \mathrm{~km}$ between the EMI and HIMU hotspots. Since the Gough-type-EMI plumes are located above the margin of the African Large Low Shear Velocity Province (LLSVP), their source reservoir could be located either within the LLSVP or represent the ambient mantle flowing against its steep outer margin. The common St. Helena-type HIMU reservoir, however, must be located within the interior or on top of the LLSVP. Both EMI type hotspot tracks began with Large Igneous Provinces (ParanaEtendeka and Karoo) that are older than the oldest HIMUtype volcanism. Seismic tomographic images show a step (bulge) at shallower depths located 1000-1500 km northeast from the African LLSVP margin. We propose that removal of material by starting plume heads from within or on the African LLSVP led to instabilities that triggered smaller secondary plumes from within or above internal portions of the LLSVP. 